\title{
Dictadura militar y construcción identitaria: La categoría 'Mujer Chilena'
}

\author{
Pablo Isla
}

Universidad de Leiden

\section{Resumen}

Este estudio analiza el rol de la mujer chilena como figura emblemática en la construcción del discurso identitario del nuevo orden político y cultural que se inició con el golpe de Estado de 1973. A través de una metodología cualitativa de análisis del discurso (Angenot, 2012), a partir de un corpus conformado por fuentes primarias y secundarias, el autor busca identificar los fundamentos heurísticos del nuevo discurso sobre la mujer y en qué medida este da cuenta de continuidades y rupturas acerca de la forma de entender el país y su identidad en torno a la idea del orden. La construcción de esta figura femenina utilizó aspectos conservadores del género que estaban relacionados con el contexto político previo al golpe de Estado y que resultaron funcionales a la concepción de orden de la Junta Militar. Se trata de una construcción discursiva y moralista que, a la postre, parece naturalizada en la cultura política de Chile.

Palabras clave: Discurso político, identidad nacional, dictadura militar chilena, mujer y política, género y política.

\section{Military dictatorship and identity construction: The 'Chilean Women’ category}

\begin{abstract}
This study examines the role of Chilean women as emblematic figure in the construction of the identity discourse of the new political and cultural order that began with the coup d'état in 1973. Through a qualitative discourse analysis methodology (Angenot, 2012), from a corpus consisting of primary and secondary sources, the author attempts to identify the heuristic bases of the new discourse on women and to what extent this discourse evidences continuities and ruptures on how to understand the country and its identity about the idea of order. The construction of this female figure used conservative gender aspects that were related to the political context prior to de coup and resulting functional with the idea of order of de military Junta. It's a discursive and moralistic construction which appears naturalized in the political culture of Chile.
\end{abstract}

Keywords: Political speech, national identity, Chilean military dictatorship, woman and politic, gender and politics.

*Dirección de correspondencia [Correspondence

address]: Pablo Isla, Universidad de Leiden

E-mail: p.a.isla.monsalve@hum.leidenuniv.nl 


\section{Introducción}

Diversas líneas de investigación durante las últimas dos décadas han comenzado a abordar diferentes áreas de la historia social de Chile a partir de dos ejes: el de la identidad nacional como constructo discursivo y el del orden normativo vinculado con su historicidad interna. El análisis que aquí se presenta procura justamente articular esas miradas analíticas particulares en relación con los antecedentes históricos y políticos de la definición discursiva de mujer como categoría identitaria durante la dictadura militar chilena. Con más énfasis que en otras épocas de la historia, debido en gran medida a su proximidad temporal y su magnitud simbólica, la dictadura militar se posicionó con diversos nudos convocantes que gravitaban en torno al orden, al enemigo interno, a la legitimidad doctrinaria o legalista y a la pretensión -aún disputada- de haber emprendido cambios de trascendencia histórica.

Desde la perspectiva del análisis del discurso (Angenot, 2012), especialmente del análisis histórico del mismo (Kendall y Wickham, 1999), en las páginas que siguen se pretende analizar y establecer los signos y símbolos de verosimilitud de lo que, según los actores de la época, se entendió como el rol preferencial y necesario de la mujer en el nuevo contexto nacional surgido del golpe de Estado. En particular, se quiere responder a la pregunta de ¿cuáles han sido los fundamentos heurísticos del nuevo discurso sobre la mujer en clave identitaria nacionalista y en qué medida este da cuenta de continuidades y rupturas acerca de la forma de entender el país y su identidad en torno a la idea del orden?

Para responder a esta pregunta se ha conformado un corpus de fuentes primarias anteriores y coetáneas a la dictadura (documentos periodísticos, textos jurídicos y documentos oficiales) y de fuentes secundarias de las décadas de 1980 y 1990. La triangulación de estas diversas fuentes permite determinar ciertos hechos relevantes y recrear el sentir y el sentido de la época a partir de la textualidad de los discursos, complementado con la descripción y el análisis que, desde distintas posiciones, han realizado quienes desde la academia han estudiado el periodo.

\section{De la ruptura al (re)establecimiento del (nuevo) orden}

Tres ideas principales orbitan en torno a la escenificación del tiempo histórico a partir del golpe de Estado de 1973: primero, la cuestión acerca de si este constituyó una continuidad o una ruptura de la tradición del país y sus mitos; segundo, la demonización del pasado inmediato (la Unidad Popular como el trauma del caos y la administración de ese trauma) y, tercero, la idea de inauguración de un nuevo tiempo nacional (la llamada segunda independencia de Chile). Estas ideas entroncan con otros dos componentes: la visión de que la empresa refundacional de la dictadura habría implicado una revolución (liberal o conservadora) y la introducción de dispositivos de control que dieron al nuevo periodo el carácter de estado de excepción ${ }^{1}$.

Consecuente con lo anterior, diversos estudios sostienen que el discurso acerca de la identidad nacional sufrió un quiebre a partir del 11 de septiembre de 1973 (Lira Kornfeld, 1991; Tocornal Montt y Vergara Reyes, 1998; Richard, 1998; Candina Polomer, 2002; Manzi et al., 2003; Fernández Droguett, 2007; Waldman Mitnick, 2009; Vilches Parra, 2016). Este quiebre habría dado paso a una reformulación de un discurso identitario oficial en donde las representaciones fueran, por tanto, funcionales al nuevo orden. De este modo, la reacción del régimen militar contra los partidarios del gobierno depuesto y contra los potenciales opositores, así como el explícito propósito de crear un nuevo orden, reforzaron o redimensionaron las categorías antagónicas de chilenos, coherente con el inicial propósito refundacional enarbolado por la Junta. Resultado de este proceso fue la fragmentación del discurso identitario nacional, puesto que quienes fueron definidos ideológicamente como los enemigos fueron objeto de medidas de marginación y eliminación.

Por otra parte, el proceso de fragmentación identitaria se reflejó en la construcción de una particular memoria colectiva, puesto que el nuevo relato de la identidad nacional suprimía unilateralmente una memoria histórica que había tolerado (más que admitido) cierta variedad de interpretaciones posibles. El desconocimiento de esta diversidad implicó el no reconocimiento del otro, toda vez que "el reconocimiento es una condición de la existencia de la identidad" (Prado y Krause, 2004: 63). El no reconocimiento operó respecto de los fundamentos de legitimidad, dignidad y memoria en el discurso de la alteridad interdicta.

Lo identitario para la dictadura militar fue coherente con un sentido inherente del deber que fundamentaba particularmente la disciplina necesaria con la que se concebía el orden, trasunto de las ideas corporativistas que inicialmente lo inspiraron: los estudiantes han de estar dedicados a sus estudios; los trabajadores deben estar centrados en sus fae-

\footnotetext{
${ }^{1}$ Diversos autores coinciden en señalar que el carácter refundacional tomó cuerpo paulatinamente, y que ello no habría sido el sentido inicial del golpe de Estado (Vergara, 1983; Varas, 1983). Para los hagiógrafos de A. Pinochet lo 'refundacional' implicaba un carácter revolucionario (Lavín, 1987; Whelan, 1993)
} 
nas por el bien del país; las mujeres han de ocuparse y preocuparse de sus labores del hogar y la familia; el soldado se encarga de defender la patria. Los partidos políticos y sus actividades constituían, en el nuevo escenario, factores de dispersión y fragmentación, ajenos a los intereses nacionales, máxime cuando se entendía que habían generado el conflicto y habían claudicado ante 'intereses foráneos'. El nuevo escenario propició una civilidad entendida como 'civismo', como 'disciplina civil', no como 'sociedad civil', concepto que en sí mismo dejaba fuera a los militares. Lo paradójico es que este desiderátum constituía una paz obtenida mediante una permanente lógica de guerra, una dicotómica visión de orden-caos que excluía la tregua, el compromiso o el acuerdo, y que se dirimía en la pugna victoria propia-derrota del enemigo. De modo que defender el orden era eliminar lo diferente, y la política era la continuación de la guerra con otros medios (Lechner, 1983).

Cabe advertir que la visión crítica y negativa hacia los partidos políticos encuentra sus orígenes ya en el militarismo mesiánico y populista de la década de 1920, con Carlos Ibáñez del Campo como uno de sus prístinos exponentes, cuando tanto la actividad política como del sistema de partidos, el gobierno y el Parlamento caían en un descrédito creciente y generalizado. Más tarde,

"La idea de la componenda, la corrupción y el aprovechamiento del control del aparato del Estado por parte de políticos profesionales, no hay que olvidar, es uno de los leit motivs de la campaña del general Ibáñez en el '52, el que tampoco por casualidad usa la escoba como símbolo de su promesa de limpiar de la corrupción política a la Administración Pública".

(Santa Cruz y Santa Cruz, 2005: 74-75).

En aquella crítica a los políticos, en los institutos armados subyacían dos ejes argumentativos: uno, emocional-nacionalista, que veía en las fuerzas armadas la esencia y unidad de los valores nacionales, por sobre diferencias de cualquier tipo que pudieran existir dentro de la población; y otro, defensivoautoritario, según el cual los partidos políticos operaban como agentes disruptivos y desarticuladores de la armónica unidad nacional ${ }^{2}$. El posterior perfilamiento ideológico de las corrientes anarquistas,

\footnotetext{
2 "Si, en principio, a todos los partidos debe suponérseles animados del mismo sentimiento patriótico, la obtención del bien colectivo, las luchas que entre ellos se producen, no deberían alcanzar el apasionamiento a que a veces llegan y que, en ocasiones, es más fuerte que ese nexo de unión que representa el haber nacido en el mismo suelo y el ser ciudadano de una misma Nación. Así se llega a las guerras civiles, que por ser guerras entre hermanos son las más sangrien-
}

socialistas y marxistas, cuya vocación internacionalista, antinacionalista, anticolonialista y antiimperialista plantearía dudas acerca de la utilidad de los ejércitos (Quiroga Zamora, 1994; Arriagada Herrera, 1999), que poseían además un origen 'foráneo', ajeno a la tradición del país y que, a su vez, propalaban el concepto de lucha de clases y vanguardia del proletariado para exacerbar a las masas, serían vistos como factores que atentaban en contra del nacionalismo unitario, para el cual 'nacional' se oponía a 'clasista'?

Ahora bien, para el disciplinamiento social necesario al nuevo discurso post 1973, Lechner (1983) advierte un disciplinamiento organizacional, a través de diversas instituciones intermedias: juntas de vecinos, centros de madres, las secretarías nacionales (de la Mujer, de la Juventud, de los Gremios), la Dirección General del Deportes y Recreación, la Defensa Civil, diversas organizaciones del voluntariado femenino y los planes y programas escolares, idóneos para el objetivo de ordenamiento funcional de la población en una comunidad jerarquizada, según sus roles 'naturales' (mujeres, jóvenes, trabajadores, deportistas, soldados, etc.), organizaciones que si bien existían en el periodo anterior, ahora no constituían representantes de una sociedad diversificada sino representaciones del Estado.

En este contexto, el discurso del nuevo orden hablaba de buenos y malos chilenos. Las mujeres fueron un centro de atención clave en el esfuerzo por definir a sectores afines con el proyecto identitario autoritario. Si la cara masculina de la nación eran el soldado y el huaso, su cara femenina era una particular representación de 'la mujer chilena'.

tas y dolorosas (revolución de 1891) y que son doblemente lamentables por los males naturales que ellas representan y por el daño espiritual que significa para la vida misma de la nación, que no puede vivir allí donde no existe la unión entre sus hijos" (Coronel Guillermo Aldana, 'El Ejército, escuela de civismo e institución de equilibrio social', Memorial del Ejército, sept.-oct., 1940, en Varas y Agüero, 1984: 63).

${ }^{3}$ Estas ideas llegarían a ser compartidas tanto por sectores nacionalistas de diverso cuño como por los diferentes grupos que confluyeron en la formación del Partido Nacional en 1966. Pese a la estabilidad político-institucional del periodo 1932-1970, y considerando como matriz del pensamiento conservador el apego a una tradición que buscaba en lo vernáculo su legitimidad cultural, la sensación de pérdida del orden y del consenso y la idealización de un pasado glorioso siempre subyacieron a la derecha chilena a lo largo de buena parte del siglo XX. 


\section{Antecedentes históricos del perfila- miento conservador de la figura 'mujer chilena'}

Dos factores fueron cruciales para este constructo: por un lado, una historia reciente en la que las mujeres habían resultado ser un sector proclive a los discursos políticos contrarios a la izquierda y un polo importante de rechazo al gobierno de la Unidad Popular; por otro, un contrapeso simbólico contra el fracaso y la cobardía de los hombres civiles, políticos, izquierdistas o antipatriotas- que habían claudicado frente al marxismo internacional.

Entre los factores históricos hay que remontarse a cuatro antecedentes. El primero de ellos es la llamada campaña del terror organizada para apoyar la candidatura presidencial de Frei Montalva en 1964 y evitar el triunfo electoral del candidato izquierdista, Salvador Allende (Kornbluh, 2003). Esta campaña se había empeñado en elaborar un vínculo orgánico entre mujer, familia y salvación nacional versus una visión demonizada de la izquierda (Lira Kornfeld, 1991; 2008) ${ }^{4}$, y fue apoyada en su diseño y financiación por Estados Unidos en el marco del fomento a las acciones anticomunistas, luego de constatar que ante el avance electoral de los partidos de la izquierda, el voto de las mujeres en Chile era más conservador que el de los hombres y tendía a crecer (Power, 2008) ${ }^{5}$. La campaña recurría a las visiones de género y anticomunismo prevalecientes en Norteamérica y a las experiencias que la misma había tenido en su aplicación en Cuba y Brasil ${ }^{6}$. El estrecho margen de votos con el que Jorge Alessandri Rodríguez había ganado las elecciones presiden-

\footnotetext{
${ }^{4}$ La campaña del terror, sobre la base de un exacerbado anticomunismo, unido a un rechazo emocional hacia los sectores populares, no eran en Chile un fenómeno novedoso. Había adquirido rasgos de defensa de los valores conservadores católicos contra la candidatura presidencial de P. Aguirre Cerda (1938) (Lira Kornfeld, 1991), y rasgos paroxísticos en los grupos anticomunistas en la campaña por la exclusión del Partido Comunista durante el gobierno de González Videla, antes de la dictación de la conocida como ley de defensa permanente de la democracia, en 1948 (Maldonado Prieto, 1989; Gómez, 1988; Correa S. et al., 2001).

5 "Cuando las chilenas votaron por primera vez en una elección presidencial, en 1952, sus votos representaban [el] $30 \%$ de todos los votos válidos. En 1958, el porcentaje femenino de los sufragios había subido a $35 \%$ y en las elecciones presidenciales de 1964 la cifra llegó a 46\%" (Power, 2008: 107). En la elección presidencial de 1964, Frei Montalva ganó gracias al elevado número de votos de mujeres que compensó la gran cifra de hombres que votaron por Allende: el primero obtuvo 6.261 votos de mujeres y 4.998 de hombres, mientras que Allende, 3.785 de mujeres y 5.217 de hombres (íd.: 132).

${ }^{6}$ Se trata, concretamente, de la operación Pedro Pan en Cuba, según la cual 20.000 niños cubanos fueron enviados por sus padres a residir en EE.UU. para no vivir bajo el comunismo, y la acción de mujeres católicas conservadoras en Brasil en 1964, que como opositoras al gobierno de João Goulart reclamaron la intervención de las fuerzas armadas (Power, 2008).
}

ciales en 1958 y la fuerza creciente de la izquierda hacían temer un próximo triunfo de Allende, por lo cual la campaña se centró en disuadir a los electores de votar por los partidos izquierdistas y presentar su proyecto político como un voto por la dictadura comunista, a la vez que intentó destacar los beneficios que traería la elección del candidato del Partido Demócrata Cristiano (PDC) ${ }^{7}$. Recurriendo a un lenguaje simple, directo y emotivo, se difundieron mensajes por radio, televisión y periódicos, además de folletos, volantes y carteles con advertencias atemorizantes, que alarmaban frente a una conspiración marxista internacional que pretendía apoderarse del país:

\begin{abstract}
"Por ejemplo, el 1 de agosto y todos los días siguientes hasta el 4 de septiembre [de 1964, día de la elección], grandes avisos aparecieron en El Mercurio con la cuenta regresiva de los días que faltaban para las elecciones, las que figuraban como una batalla entre las fuerzas del bien y del mal, entre el patriotismo y la traición a la patria. Un aviso, calculado para infundir en el lector una impresión de fatalidad, clamaba con letras de gran tamaño: «FFaltan 34 días!». Debajo del titular, el texto rezaba: « ¿Podemos aceptar que el marxismo internacional se apropie de una parte de este territorio que siempre ha sido uno solo para todos los chilenos? A ellos, los hombres libres respondemos: Después del 4 de septiembre, Chile seguirá siendo chileno»"
\end{abstract}

(Power, 2008: 105).

Las alusiones a la identidad nacional estuvieron también presentes, como el aviso "Escucha Campesino Chileno, Encarnas la mayor tradición de la Patria y eres como un símbolo de la chilenidad", aparecido en El Mercurio, el 10 de agosto de 1964 (íd.: 106). Pero, sin duda, las apelaciones a la familia y a los hijos constituyeron mensajes dirigidos a los padres de familia y muy claramente, a las mujeres:

\footnotetext{
${ }^{7}$ Para las elecciones de 1964 la derecha se hallaba en una profunda crisis. Julio Durán, militante del Partido Radical, fue apoyado por radicales, liberales y conservadores reunidos en el Frente Democrático. Sin embargo, luego del episodio electoral conocido como el Naranjazo (15 de marzo de 1964), la derecha decidió apoyar al mal menor, es decir, a Frei Montalva. El Naranjazo, una elección complementaria producida por la muerte del diputado socialista de Curicó, Óscar Naranjo, dio como resultado un sorpresivo triunfo a su hijo, de la misma tienda, lo que alarmó a la derecha y a la Democracia Cristiana de cara a las elecciones presidenciales en ciernes.
} 
"Chile en la encrucijada. Para ti la palabra LIBERTAD significa el derecho a escoger tu Trabajo, a expresar tu opinión, a convivir con tu familia, a formar espiritualmente a tus hijos. ¿Estás tú dispuesto a sacrificar los derechos que otorga la Libertad a cambio de la aventura marxista? Piensa en el futuro de tus hijos"

(El Mercurio, 2 de agosto de 1964, íd.: 106-107).

"Escucha, mujer chilena. Como madre, como esposa, como hija, tienes hoy una gran responsabilidad. ¿Has pensado en la unidad de tu hogar, en el futuro de tus hijos, en la felicidad de tus hijos? Recuerda que lo más valioso de tu vida está en peligro. ¡Y recuerda que la alternativa es Democracia o Marxismo!"

(El Mercurio, 5 de agosto de 1964, íd.: 107).

Estas apelaciones a la salvación frente al mal hacían sentido en una sociedad en la que la actividad política era claramente patrimonio masculino y en la que el papel de la mujer estaba circunscrito a los roles tradicionales del trabajo doméstico y la crianza de los hijos ${ }^{8}$. Conscientes de esa situación, los encargados de la campaña identificaron la radio - entonces, monopolizada por partidos de derecha (Hurtado et al., 1989)- como el medio más idóneo para llegar directamente a las mujeres:

"Un aviso radial, por ejemplo, comenzaba con el ruido de una ametralladora, luego una voz femenina que gritaba: «iHan matado a mi hijo! ¡Los comunistas!». Con voz emocionada, el locutor de la radio luego decía: «El comunismo sólo ofrece sangre y dolor. Para que esto no suceda en Chile elijamos presidente a Eduardo Frei»"

(Power, 2008: 108).

El apoyo político y financiero al PDC chileno estuvo basado en la consideración de que éste era el mejor aliado contra el comunismo y para emprender los cambios modernizadores que evitaran la revolución social (Labarca Goddard, 1968; Power, 2008).

Un segundo antecedente, relacionado con lo anterior, es que el PDC venía desarrollando acciones

8 "En 1970, sólo $20 \%$ de las mujeres trabajaban fuera de su casa, y la mayoría de las que lo hacían eran o trabajadoras domésticas o profesionistas de clase media, no obreras" (Power, 1997: 251). Según otra fuente, sólo el 14,3\% de las mujeres que trabajaban recibía remuneración fuera del hogar en 1970, la cifra más baja desde 1950 (con un 28,9\%). La misma fuente registra: $23,5 \%$ en $1955 ; 18,1 \%$ en 1960 , y 15,1\% en 1965 (Valdés y Gomáriz, 1992: 40). dirigidas a las mujeres, especialmente a mujeres pobres vinculadas a la Iglesia Católica y a los centros de madres. La Sección Femenina del partido y los Comités de Mujeres por Frei concebían estos centros de madres como un espacio de desarrollo económico y social de las mujeres y también como apoyo electoral y expansión de su base social. Una vez en el gobierno, el Programa de Promoción Popular impulsó una campaña masiva para organizar a los sectores pobres rurales y urbanos e integrarlos al país. Las juntas de vecinos y los centros de madres resultaron las modalidades propiciadas por esa política. Mediante un órgano nacional (CEMA, 1964) la Primera Dama presidió los centros de madres.

"La Democracia Cristiana y sus ideólogos planteaban la necesidad de integrar a un gran sector social, urbano y rural, 'marginado' del proceso político y de la economía nacional desde la conquista española. Habían cristalizado así dos mundos apartes: los integrados a la economía moderna y al sistema democrático y los 'marginales' que no participan de la sociedad, ni de los bienes, ni de sus servicios (participación pasiva) ni de la toma de decisiones (participación activa). La evaluación política y social era de cierta peligrosidad: la economía moderna con su producción de bienes de consumo hacía las veces de una vitrina que podría estallar por la acción de quienes deseaban participar, al menos en el consumo. Para evitarlo era urgente integrarlos (...). Por otra parte, la integración de estos sectores y el logro de las metas propuestas requería desarrollar profundas reformas en la estructura económico-social y la movilización organizada de estos sectores marginales"

(Valdés et al., 1989: 13).

De esta forma, las mujeres comenzaban a ser incluidas en una organización sólo femenina y de cobertura nacional, que tendía a superar la postergación de que habían sido objeto y a potenciar su capacidad para obtener ingresos $\operatorname{propios}^{9}$, aunque sin exceder los límites tradicionales de la época: se trataba básicamente de amas de casa (dueñas de casa en la nomenclatura local) en su papel de madres que colaboraban al ingreso familiar. Los rasgos

\footnotetext{
${ }^{9}$ Durante el gobierno de E. Frei Montalva (1964-1970), "para alcanzar estos objetivos CEMA estableció, con otras instituciones estatales, convenios que posibilitaron la venta de 70 mil máquinas de coser a mujeres de escasos recursos" (Valdés et al., 1989: 17-18). "Las máquinas permitieron que las mujeres no sólo confeccionaran ropa y artículos de uso doméstico para sus familias, con lo que redujeron los gastos, sino también que produjeran artículos para la venta (...). Además, las máquinas de coser introdujeron a estas mujeres directamente a la tecnología moderna y las llevó a verse como beneficiarias directas de un programa nacional patrocinado por el Estado y dirigido a la mujer" (Power, 2008: 136).
} 
de clientelismo y paternalismo políticos y de estructura jerárquica clasista eran manifiestos.

Cuando la Unidad Popular asumió el gobierno, existía una amplia red de centros de madres agrupados en uniones comunales, federaciones provinciales, que a su vez constituían una Confederación Nacional, y se extendían especialmente en los barrios pobres y de sectores de clase media baja ${ }^{10}$. "En 1970 existían alrededor de 9.000 centros de madres que agrupaban a 450.000 mujeres" (Aylwin et al., 1986: 38). Las estimaciones para 1973 varían: "en 1973 existían a lo largo del país 20.000 centros de madres con cerca de 1.000 .000 de socias, y seguían multiplicándose y adquiriendo diferentes orientaciones políticas" (Gaviola et al., 1988: 86); con más datos, "otras autoras dan una cifra de 30.000 centros de madres para fines de 1973. Pensamos que efectivamente superaron los 20.000 por cuanto en 1974, tras la represión y persecución de organizaciones y dirigentas, aún quedaban 20.000 centros afiliados a CEMA-Chile" [sic] (Valdés et al., 1989: 28).

Si bien durante los años de la Unidad Popular los centros de madres seguían creciendo con el apoyo del Gobierno, en paralelo aumentaba el debate sobre su orientación política y sus objetivos programáticos. Aunque decían observar independencia política y religiosa, las posiciones ideológicas en liza eran consustanciales a su origen y fueron determinantes en el posicionamiento frente a la coyuntura política $^{11}$ :

"El elevado número de mujeres que participaban en los centros, muchas de las cuales conservaron su adhesión al partido, aunque Eduardo Frei M. ya no fuera presidente, aseguró al PDC una base masiva. Cuando se inició la oposición activa del PDC contra el gobierno de la UP, el partido recurrió a los Centros de Madres para llamar a las mujeres a participar en sus actividades antiallendistas"

(Power, 2008: 141).

La Unidad Popular también contó con centros de madres afines, aunque su política hacia la mujer popular fue menos estructurada y menos difundida que la del gobierno democratacristiano. La mujer no estaba concebida como sujeto independiente de

\footnotetext{
${ }^{10}$ Cada centro de madres reunía entre 30 y 40 mujeres residentes en el sector y era dirigido generalmente por mujeres de los sectores acomodados (Aylwin et al., 1986), las que tendieron a institucionalizar un tipo específico de voluntariado (Valdés et al., 1989).

11 "Aquellos centros de madres que se sentían identificados con la Unidad Popular trabajaban estrechamente vinculados a COCEMA, mientras que otros, adherentes a la democracia cristiana, se mantuvieron coordinados en una estructura independiente del gobierno" (Aylwin et al., 1986: 38).
}

la familia ${ }^{12}$. La innovación y la diferenciación de su proyecto en la materia chocaban, además, con una lógica de género marcada por la tradición patriar$\mathrm{cal}^{13}$ :

"Se hace necesario entregar más atribuciones, recursos y poder de decisión a las organizaciones a través de las cuales se expresan hoy día las mujeres, y entre ellas a las Uniones Comunales, Federaciones Provinciales y Confederación Nacional de Centros de Madres, las Comisiones Femeninas de todos los consejos de la Central Única de Trabajadores y organizaciones de la mujer.

La igualdad plena de la mujer, la protección de su familia e hijos, la defensa de la madre soltera, su igualdad de oportunidades y remuneración en el trabajo, son conquistas y aspiraciones que la Unidad Popular ha impulsado con decisión. Sus resultados serán necesariamente limitados en tanto no se profundicen los cambios del sistema mismo y se avance en la construcción de una sociedad socialista, la que hace que la mujer sea objetivamente la más interesada en esa transformación revolucionaria $(\ldots)$

Sin embargo, estamos conscientes de que aún esta medida no se ha cumplido en plenitud, debido al burocratismo y la falta de una comprensión integral de su importancia, lo que estamos dispuestos a corregir para que nuestras medidas no queden en el papel. Tenemos el decidido propósito de asegurar a cada niño, independientemente de la situación ocupacional o el ingreso de sus padres, un número creciente de productos y servicios"

(Unidad Popular, s/f: 66, citado por Valdés et al., 1989: 28).

En los años de la Unidad Popular se sumaban al clientelismo y asistencialismo políticos preexistentes la complementariedad y la lucha en el espacio político, expresadas en el 'poder popular'. Eran formas coexistentes de participación social y de relación con el Estado y los partidos políticos (Valdés et al., 1989). Lo cierto es que las organizaciones de mujeres se enfrentaron con vehemencia contra el

\footnotetext{
${ }^{12}$ De hecho, uno de los proyectos de la Unidad Popular referidos a política social hacia las mujeres se expresaba en el proyecto de ley que crearía el Ministerio de Protección a la Familia, y que aglutinaría a todas las dependencias relacionadas con la infancia, la mujer y la familia. En forma paralela, por decreto supremo se creó, en septiembre de 1972, la Secretaría Nacional de la Mujer como órgano asesor para la elaboración y ejecución de planes y políticas relativas a la incorporación de la mujer y la atención al niño (Valdés et al., 1989).

${ }^{13}$ Durante la Unidad Popular los roles de género y la sexualidad también fueron objeto de debate y fueron abordados por la política pública, en el entendido de mejorar las condiciones de vida de la clase trabajadora. Los cambios culturales propiciaron su abordaje. Para un análisis de las posturas que partidarios y opositores de la Unida Popular tenían al respecto, véase Power (1997).
} 
gobierno de Allende conforme se agudizaba la crisis de desabastecimiento, principalmente de alimentos. Ajenas a las causas que generaban el acaparamiento y el desabastecimiento (una campaña orquestada por la oposición), las mujeres organizadas en la oposición adjudicaban únicamente la responsabilidad de esa crisis al Gobierno, como una especie de profecía autocumplida de que el marxismo les quitaría hasta el pan para sus hijos, además de su fuerte tendencia a resistir los cambios propuestos por el gobierno de la Unidad Popular.

Un tercer antecedente fue el hecho de que, en paralelo al gobierno del PDC, la derecha había comenzado un proceso de rearticulación al alero del Partido Nacional, cuyo sello, más beligerante que sus antecesores, se combinó con un estilo más moderno que le atribuyó mayor importancia a la participación y movilización de la mujer (Power, 2008). Confiados en que la elección presidencial de 1970 les sería más favorable, emprendieron en favor de su candidato ?J. Alessandri Rodríguez? una ardua campaña, uno de cuyos ejes fue el papel de la mujer. Acción Mujeres de Chile y Chile Joven patrocinaron una segunda versión de la campaña del terror utilizada para la elección de 1964. Las estrategias propagandísticas y las ideas centrales fueron las mismas: alarmismo frente al marxismo, anticomunismo con apelación a valores nacionalistas, pavor al expolio de las riquezas nacionales, amenaza del caos moral y la destrucción de los valores que sustentaban a la familia, adoctrinamiento y servidumbre de los hijos a manos del comunismo cubano y moscovita, etc., vale decir, un despliegue mediático premonitorio del lenguaje que la derecha habría de usar para atacar a la Unidad Popular cuando ésta llegase al poder (Power, 2008) ${ }^{14}$.

El rol central de las mujeres se expresó en que éstas no eran políticas. La política venía siendo resemantizada por la derecha desde el momento de

\footnotetext{
${ }^{14}$ Miembros de Acción Mujeres de Chile - sin vínculo formal aparente con el Partido Nacional- recurrieron a la Agencia Andalién para el diseño de esta campaña, masiva y de alcance nacional, que se difundió por radio, prensa, por avisos en espacios públicos, folletos y volantes entre los meses de mayo, junio y julio de 1970. Fue financiada con apoyo de partidarios de la derecha y con fondos del gobierno estadounidenses para las actuaciones encubiertas dirigidas a evitar el triunfo electoral de Allende. La campaña terminó cuando miembros de las Juventudes Comunistas irrumpieron en las oficinas de la agencia el 21 de julio de 1970, sustrayendo documentación que demostraba la participación de la derecha en la campaña, material que fue distribuido a periodistas y a parlamentarios. ?Ni la Agencia Andalién ni ningún parlamentario del Congreso de Chile negaron la legitimidad del material del que se apoderaron los militantes de las Juventudes" (Power, 2008: 157). Este hecho dio lugar tanto a investigaciones del Comité del Senado de EE.UU. (Senate Select Committee, Covert Action: Report, 1st Session, 4-5/12/1975) como de la Cámara de Diputados de Chile (Cámara de Diputados, Legislatura Ordinaria, sesión 25, 19/08/1970, y sesión 38, 06/01/1972). (Cf. Kornbluh, 2003).
}

su declive electoral en la década de 1950, coetáneo con el progresivo avance de los partidos ideológicoreformistas. La política y los políticos adquirieron una connotación peyorativa sobre la base de considerar su actividad como propia de corruptelas y de intereses parciales y mezquinos, hasta llegar a su franca criminalización ${ }^{15}$. En este campo semántico los conceptos como 'influencias foráneas', 'intereses extranjeros', 'agentes del comunismo internacional', 'enemigos de la patria' o 'antichilenos' entronca con los discursos militaristas, católico-nacionalistas y liberal-conservadores gestados en el país desde la década de 1920 para motejar a las corrientes ideológicas contrarias. Las mujeres, que en su gran mayoría no militaban formalmente en la política ni tenían espacios significativos en las orgánicas partidarias, eran chilenas, no políticas. Su voz era auténticamente la voz y el sentir no del pueblo -a esas alturas, de clara connotación marxista-, sino del país interno y real, la familia. A las mujeres "no les interesaba la política", les interesaba "el bienestar de sus hijos y de su familia", según los tópicos de la época, lo que las dotaba de una capacidad redentora. De allí la relevancia simbólica de la frase con la que concluían los avisos radiales de la campaña patrocinada por Acción Mujeres de Chile en 1970: "Mujer chilena: el destino de la Patria está en tus manos" (Power, 2008: 293).

Desde el día siguiente a la elección presidencial de 1970 las mujeres opositoras al candidato socialista exacerbaron su campaña para evitar su eventual ratificación por el Congreso Pleno, como ocurrió con las mujeres de la clase alta vinculadas al Partido Nacional:

\begin{abstract}
"Impacientes ante la que percibían como pasividad de los hombres del PN, decidieron tomar las cosas en sus propias manos. A partir del 5 de septiembre, el día siguiente al de las elecciones, iniciaron una campaña de presionar a la democracia para que votara contra Salvador Allende. Esa tarde y todas las tardes, hasta que el Congreso lo confirmó en la presidencia, grupos de mujeres desfilaron frente al palacio presidencial de La Moneda; vestidas de luto por la muerte inminente de la democracia en Chile, pedían al presidente Frei «no entregar el país al comunismo»" [sic]
\end{abstract}

(Power, 2008: 165-166).

El cuarto antecedente, el episodio más bullado y trascendente después de un primer año de gobierno de la Unidad Popular sin grandes demostraciones ni reacciones opositoras, corresponde a la Marcha de

\footnotetext{
${ }^{15}$ Del mismo modo, la campaña presidencial de Alessandri Rodríguez se presentaba, en 1970, como la candidatura de una figura independiente, no la de un político.
} 
las cacerolas vacías ( $1^{0}$ de diciembre de 1971), organizada como protesta contra la política de la UP y contra la larga presencia de Fidel Castro en el país, entonces de visita oficial ${ }^{16}$. En cuanto a su impacto, constituyó un "verdadero hito que marcó simbólicamente el período a partir de la imagen de estas mujeres marchando por la calle con una olla, sartén o cualquier otro utensilio de cocina como muestra de repudio al desabastecimiento de productos básicos" (Godoy Ramos, 2011: 5) ${ }^{17}$. En lo político, significó para las participantes vencer la inercia y la confusión de los partidos opositores a Allende desde hacía un año, de modo que "la marcha revitalizó [a] la oposición y convenció a las mujeres conservadoras de que ellas constituían una fuerza dinámica en la política chilena" (Power, 2008: 168).

La marcha no sólo reunió a mujeres militantes y simpatizantes de la derecha (PN, Patria y Libertad), sino también a militantes y simpatizantes democratacristianas y a otras opositoras al gobierno. En la voz de sus protagonistas la forma como se gestó y sus niveles de autoría, liderazgo y autonomía de los partidos ${ }^{18}$ son confusos y contradictorios, pero sí coinciden en que la marcha alcanzó niveles casi míticos al interior de la oposición a Allende y la UP (Arancibia Clavel y Dittborn, 2008; Power, 2008). Para los partidarios del Gobierno, la marcha no había sido más que un montaje de la élite, una marcha de mujeres del barrio alto que por primera vez en su vida tenían en sus manos una olla, "una farsa de los momios" y el "freísmo" 19, que al calor de los incidentes con sus partidarios y la policía, había demostrado la "violencia fascista", como refería El Siglo en su edición

\footnotetext{
16 “"Allende, escucha, las mujeres somos muchas». «Que se vaya con Fidel». «Fidel a la olla, aliñado con cebolla». «Si no se va luego Fidel no va a comer ni él» (Gritos y lemas del Cacerolazo del 1 de diciembre de 1971, que reunió a cinco mil mujeres en el centro de Santiago para protestar contra el desabastecimiento y la visita de Fidel Castro a Chile)" (Revista Qué Pasa, edición especial 25 años, 3/08/1996, citado por Godoy Ramos, 2011: 13).

17 "Imagen que paradojalmente reaparece varios años después, pero esta vez en la figura de las mujeres opositoras a la dictadura" (Godoy Ramos, 2011: 5-6).

${ }^{18} \mathrm{La}$ marcha estuvo flanqueada y protegida en todo su recorrido por militantes de Patria y Libertad, del PN y del PDC, como se difundió en la prensa de la época. Como señala Power (2008) la marcha fue autorizada por la Intendencia de Santiago a petición previa de un grupo de mujeres lideradas por Sylvia Alessandri, diputada del PN, y convocada por los periódicos derechistas El Mercurio y Tribuna, con el nombre de 'Marcha de la mujer chilena'?', y más tarde 'Marcha de las cacerolas vacías'?', remarcando su carácter apolítico, popular y transversal para oponerse al caos, al odio, al totalitarismo y a la escasez de alimentos. Subyacía en el mensaje la idea de que se convocaba a la mujer chilena que deseaba darle de comer a sus hijos. Para una versión alarmista y contraria a la UP sobre estos hechos, véase Arancibia Clavel y Dittborn (2008).

${ }^{19} \mathrm{El}$ freísmo era, en la jerga política de entonces, la línea conservadora liderada por Frei Montalva al interior del PDC.
}

del 2 de diciembre de ese año ${ }^{20}$. Para el Gobierno, las mujeres habían sido utilizadas por las fuerzas reaccionarias y la burguesía en su escalada fascista. Luis Corvalán, secretario general del Partido Comunista, afirmó al respecto en la edición de El Siglo del 14 de diciembre de ese año:

\begin{abstract}
"Emporios, supermercados, de todo hay en Providencia, Las Condes y Vitacura. Ningún hogar de la burguesía carece de refrigeradores. Y la mayoría de las mujeres que acudieron a tal marcha, además de tener los pulmones vírgenes porque nunca le han trabajado un día a nadie, no tienen idea de lo que es cocinar y lavar ollas"
\end{abstract}

(Power, 2008: 183).

Consecuencia del éxito de la Marcha de las cacerolas vacías fue la creación, a inicios de 1972, de la organización Poder Femenino (PF), una especie de comité coordinador de actividades contra el Gobierno que mantenía autonomía de los partidos políticos, pero sí estrechos vínculos de colaboración a través de un consejo coordinador formado por delegados de éstos y de gremios y organizaciones femeninas afines ${ }^{21}$. Impulsado y liderado por mujeres de Acción Mujeres de Chile, pretendía ser un movimiento transversal, pluriclasista -independientemente de la extracción social de sus líderes-, aglutinado en torno al rol de la mujer tradicional: madre y esposa. Los elementos nacionalistas y la concepción esencialista de la mujer chilena como un sujeto histórico inalterable, reservorio de los valores ancestrales de la nacionalidad, alimentó la necesidad de legitimidad y proyección de su discurso, en estrecha combinación con los lugares comunes acerca de la maternidad y la familia. Un elemento reiterado posteriormente por Poder Femenino (Donoso, 1974), está presente en una carta que mujeres de la comuna de Conchalí, participantes en

\footnotetext{
${ }^{20}$ Sin embargo, las consecuencias políticas de la marcha fueron importantes; entre otras, significó la destitución por juicio político (fallado el 22 de enero de 1972) del ministro del interior José Tohá, acusado de violar la Constitución y la ley y comprometer gravemente la seguridad de la nación al no haber garantizado la seguridad durante la marcha y haber permitido la actuación en ella de grupos armados de izquierda y haber decretado la detención arbitraria de personas.

${ }^{21}$ María Correa Morandé y Elena Larraín actuaron como fundadoras. El consejo coordinador contó con delegados de partidos como el PN, el PDC, el PADENA, la Izquierda Radical y la Democracia Radical; de los gremios, de la sección femenina de SOL, Patria y Libertad, de las organizaciones Javiera Carrera, UNAFE, Unión Cívica Democrática, Unión de Mujeres Libres, y de mujeres empresarias y profesionales sin filiación política. El vínculo con las bases en sectores populares se logró a través de los centros de madres controlados por el PDC, y la relación con las fuerzas armadas, a través del PN, cuyos parlamentarios integraban la Comisión de Defensa en el Congreso (Power, 2008).
} 
la Marcha de las cacerolas vacías, enviaron al presidente Allende para reclamar por la violencia y los insultos de que habían sido víctimas durante la manifestación. La carta, publicada en el periódico La Prensa en su edición del 5 de diciembre de 1971, terminaba con la siguiente frase: "No se olvide Ud. que nuestras antepasadas fueron Inés de Suárez, Javiera Carrera y Paula Jaraquemada" (Power, 2008: 189).

El argumento no es un detalle anodino ni retórico. En la ancestralidad del origen fundamentaban la legitimidad moral y patriótica de su reclamo. Aquí lo patriótico no es más que la dimensión nacional de la moral. De este modo, la especificidad de la coyuntura no era más que un síntoma del único sentido posible de la historia. Revela un posicionamiento frente a la identidad, la pertenencia/apropiación del pasado y la defensa de una tradición esencializada en clave anticomunista respecto de la cual la cultura de izquierda y el gobierno de la UP no habían elaborado respuestas. La izquierda, de esta manera, aparecía ante el discurso de las mujeres opositoras como intrusa en el escenario de la historia y los valores nacionales 'auténticos'. A su modo, además, las opositoras al Gobierno superponían la lógica de género que les permitía quebrar la lógica de clase con la que razonaba el proyecto político de la UP.

La agudización de la crisis económica y política no hizo sino favorecer el desarrollo de Poder Femenino, tratando de ampliar su base de apoyo entre mujeres de sectores obreros y pobres, para así desvirtuar, o al menos controvertir, la imagen de que el gobierno socialista era el gobierno de la clase trabajadora. La elección parlamentaria de marzo de 1973, que no logró dar a la oposición el quórum para una acusación constitucional contra Allende, volcó a los opositores a su estrategia alternativa: el derrocamiento a través de la intervención militar.

Ahora bien, un aspecto es la visibilidad y la resonancia que tuvieron las actividades de las mujeres opositoras y otra, la estructura de tendencias de votación de la población. Si bien Poder Femenino afianzó una alianza entre el centro político y la derecha, que habían concurrido divididos en la elección presidencial de 1970, e incorporó a mujeres a la actividad política, la elección parlamentaria de 1973 demostró que más mujeres votaron por la Unidad Popular que en 1970, pese a la crisis económica y a la alianza política PN-PDC conocida como Confederación de la Democracia $(\mathrm{CODE})^{22}$.

\footnotetext{
${ }^{22}$ Según las cifras oficiales entregadas por la Dirección del Registro Electoral, en la elección presidencial de 1970, el $31 \%$ de las mujeres votó por Salvador Allende, mientras que, en las elecciones ordinarias al Congreso Nacional de marzo de 1973 , el $39 \%$ de ellas votó por los candidatos de la Unidad Popular. Estudios como el de Sigmund (1977) demuestran que por sobre el factor sexo/género mantuvo su predominio
}

\section{El ethos de la mujer chilena en el Chile militar}

Además de su perfilamiento como sector opositor a la Unidad Popular - delineado en los cuatro antecedentes reseñados-, hubo otro aspecto importante de las mujeres como recurso del discurso político identitario empleado luego por el régimen militar, y que subyace a lo ya expuesto: el atribuir a la mujer chilena un ethos conveniente a una visión militarista del género, algo así como la reserva moral de la nación. Como aguerridas defensoras de la familia, y por esta vía, de la Patria, y dada la superioridad moral que les brinda su condición de madres, son capaces de sacar fuerzas de flaquezas para poner las cosas en su sitio cuando los hombres - políticos, civiles y militares incluidos-, se muestran pusilánimes e ineficientes en defender el rumbo y el honor de Chile. Según esta lógica, la mujer, abnegado baluarte, hace patria en la cotidianidad casi anónima del hogar, pero despliega con arrojo su valor en la activista -apolítica, pero patriota- que hay en ella como última instancia para exigir justicia y orden. Esta figura, consciente de la importancia social que se le atribuye y exige a la masculinidad, interviene para enrostrarle a los chilenos "lo poco hombre que han sido" cuando no han defendido a Chile del marxismo. Los términos marxista, comunista o izquierdista adquieren así un carácter disfémico, peyorativo, malsonante que permite atribuirles a dichos sujetos una virilidad dudosa o deficitaria.

Desde la oposición a Allende, acciones con este contenido fueron numerosas: los opositores decían que durante la Marcha de las cacerolas vacías el Gobierno habría sido capaz de atacar a mujeres indefensas, lo que demostraba la falta de hombría de las autoridades; un incidente en pleno tránsito entre una mujer en su automóvil y el comandante en jefe del Ejército Carlos Prat, ventilado por la prensa opositora, habría significado que éste, alarmado, descendiera de su auto y la enfrentase con su pistola, siendo humillado por testigos y prensa por haber querido supuestamente atacar a una dama indefensa; un numeroso grupo de mujeres, entre ellas varias esposas de generales, entregaron una carta a Sofía Cuthbert, esposa del general Carlos Prat, bochorno que desencadenó la renuncia de éste. Pero, la acción más llamativa fue la de las mujeres contra los militares de todos los rangos, en la que éstas les enrostraban su falta de hombría al no intervenir contra el Gobierno, acudiendo a los cuarteles para lanzarle maíz y plumas, dando a entender que los consideraban gallinas y maricas por no saber defender a sus mujeres (madres, novias, esposas o hijas) frente a un gobierno de fracasados que llevaba al país

la estructura de clase en la tendencia de voto. 
al abismo ${ }^{23}$. Allende mismo era representado, en bromas, pullas y maledicencias, como un impotente sexual, como en la consigna de "La Tencha nos decía que Allende no servía", coreada por las opositoras en sus manifestaciones (Montecinos, 1997: $82)$.

De este modo el movimiento conformado por el conjunto de organizaciones femeninas opositoras a la Unidad Popular aludió a una forma dual de entender el papel de la mujer en la política y en lo político, pues tanto fomentaba su empoderamiento y presencia en el espacio público, como su reclamo por el restablecimiento de un orden que las protegiese en sus roles familiares más tradicionales. Como señala Montecino, este movimiento

\begin{abstract}
"inaugura un modo de protesta que arranca desde la casa, desde el espacio ocupado por la madre, que se derrama hacia la calle con el uso de sus utensilios domésticos que se trasladan a lo público. La utilización del 'ruido doméstico' como lenguaje no articulado y difuso que se desborda fuera de la casa y copa la calle, da cuenta de la operatoria de un mecanismo de representación que funciona más que como argumento reflexivo como argumento de la emoción y de la cognición. El ruido de las cacerolas vacías es el ruido-lenguaje de la insubordinación de la madre ante la amenaza del caos. Si la madre protesta es porque su propio orden (el cotidiano) está cuestionado"
\end{abstract}

(Montecinos, 1997: 91).

Un año después del golpe de Estado, Poder Femenino y otras organizaciones análogas se disolvieron a instancias del propio gobierno ${ }^{24}$, aunque muchas de sus integrantes se mantuvieron como apoyo del régimen a través del voluntariado femenino. La misión estaba cumplida y los militares -los hombreshabían logrado estar a la altura de las circunstancias después de haber oído sus súplicas. Entonces los militares tenían otros planes para ellas, con más

\footnotetext{
${ }^{23}$ Esta acción correspondió a un plan coordinado de integrantes de Poder Femenino, SOL y Patria y Libertad, realizada entre los meses de marzo y septiembre de 1973 ante los cuarteles. Además, enviaban sobres con plumas a los militares, y mensajes con la palabra 'Yacarta', en alusión a la capital de Indonesia donde un golpe de Estado en 1965 había provocado el asesinato de miles de comunistas a manos de los militares golpistas (Power, 2008).

24 “Por qué las Fuerzas Armadas disolvieron PF? No podían haber dudado del apoyo que las mujeres dieron al golpe ni su disposición a participar en el proyecto de reconstrucción nacional, pero PF contrariaba muchos de los preceptos fundamentales que las Fuerzas Armadas sostenían acerca del papel de la mujer en la sociedad. No era una organización feminista, pero funcionaba con un grado de independencia que a los uniformados les pareció inaceptable. Participar en la organización había abierto a las mujeres nuevos horizontes" (Power, 2008: 265-266).
}

de disciplina y menos de empoderamiento. Se iniciaba un periodo en el que "mujer y fuerzas armadas están indisolublemente unidas mediante un vínculo espiritual que les permite gestar, mantener y proyectar a la Gran Familia Chilena" (Munizaga, 1983: 44). En analogía con un supuesto inherente rol mariano, en la nueva etapa, la mujer, colaboradora de la reconstrucción nacional, ayudaría a aliviar y explicar los sacrificios que esta reconstrucción implicaba, pero desde un rol subordinado, ya que, si eran madres, no debían olvidar que, también, eran esposas. Para evitar la disensión era necesario recurrir una y otra vez a la memoria del trauma, única forma de sobrellevar los esfuerzos de la reconstrucción. Lo decía A. Pinochet en su discurso de marzo de 1974:

\begin{abstract}
"Las madres chilenas han advertido que donde ayer había corrupción hoy existe dignidad, y donde reinaba la angustia de la desesperanza hoy se vive un dolor compensado por signos de fecundidad"
\end{abstract}

(Pinochet Ugarte, 1974a: 44).

Y lo repetía, quince años después del golpe, una exintegrante de Poder Femenino:

"Ni yo ni mi marido somos políticos. No hemos participado nunca en un partido, pero yo ingresé al Poder Femenino para luchar contra el marxismo. Éramos todas mujeres casadas que no queríamos que nuestros hijos, ni nuestros maridos, ni nosotras mismas tuviéramos que sufrir las pellejerías del marxismo, porque es realmente horrendo. Tiene cosas terribles, sobre todo contra la libertad. En el marxismo uno no puede educar a los hijos como quiere, sino como el partido lo decreta; los niños ya no son de los padres, llegada cierta edad, el partido los pesca y los maneja"

(Pinochetista hasta el final, Elena Tesser de Villaseca, en Politzer Kerekes, 1988: 148).

Capitalizando a su favor el anticomunismo de este mundo femenino, el régimen militar dispuso que el nuevo lugar de la mujer estuviera controlado centralmente por dos organismos, la Secretaría Nacional de la Mujer y CEMA-Chile, ambos presididos por Lucía Hiriart, en su cargo de Primera Dama de la Nación. En torno a ella se potenció un amplio arco de voluntariado, las damas identificadas con algún color relacionado con un fin benéfico transformado en acción asistencial, con tintes paternalistas y clientelares en el marco de la propaganda oficial. 
El régimen se esmeró en construir una idea icónica de la mujer chilena, especialmente en afiches y fotografías publicitarias de sus fines (Berríos Muñoz, 2009). La llamada Campaña de Reconstrucción Nacional contó con propaganda impresa ampliamente difundida en los periódicos desde octubre de 1973, y apeló a la lealtad y compromiso de la mujer que plantó cara al marxismo. El afiche promocional contaba con la imagen de dos manos, una masculina a la izquierda, símbolo del Ejército, que ponía una sortija en el dedo anular de una mano femenina, a la derecha, con el diseño de la bandera nacional en el puño de la manga, simbolizando la Patria. A continuación, se leía el siguiente texto:

"Comprométase con Chile. Comprométase con la Patria, llevando su aporte, cualquiera que éste sea, a todos los bancos del país. Contribuya a la restauración nacional, ayudando a financiar la Caja Fiscal para dar prosperidad a todos los chilenos"

(El Mercurio, Santiago, 2 de octubre de 1973).

Para allegar fondos a la reconstrucción se hizo un llamado a los chilenos para que donasen sus sortijas de matrimonio con la finalidad de reemplazar las reservas de oro del Banco Central que habían sido 'robadas por los marxistas'. Miles de personas, sobre todo mujeres, donaron sus sortijas y a cambio recibieron anillos de cobre. También muchos donaron dinero y valiosas joyas. Un decreto ley facilitó las donaciones realizadas al Estado con el fin de cooperar a la recuperación económica del país ${ }^{25}$, dando a entender en sus considerandos que era necesario regular jurídicamente un fenómeno espontáneo de apoyo al nuevo gobierno:

\begin{abstract}
"Vistos:
$1^{\circ}$ Lo dispuesto en el Decreto Ley 1 , de 11 de septiembre de 1973 ;

$2^{\circ}$ Que la ciudadanía ha iniciado en forma espontánea una erogación en especies, valores y dinero destinada a contribuir a los propósitos de la Junta de Gobierno encaminados a recuperar económicamente a la Nación, y

$3^{\circ}$ Que siendo indispensable facilitar esta manifestación cívica de bien público, liberando dichas erogaciones de tributación y de trámites que pudieran entrabarlas, la Junta de Gobierno de la República de Chile ha acordado dictar el siguiente Decreto Ley"
\end{abstract}

(Diario Oficial, 16 de octubre de 1973).

\footnotetext{
${ }^{25}$ Se trata del D.L. No 45 (promulgado el 24/09/1973 y publicado el 16/10/1973), que "contiene normas que facilitan la donación para la reconstrucción nacional, entre otras medidas, las beneficia con exención de impuestos".
}

En 1974 la Empresa Nacional de Minería (ENAMI) acuñó dos mil medallas de plata como homenaje al 11 de septiembre y a la participación de la mujer en el movimiento restaurador; "la medalla tiene grabada una figura femenina y la leyenda reconstruyamos la paz" (Candina Polomer, 2002: 16). Con la imagen de una mujer corriendo con los brazos abiertos, en 1974 apareció un afiche con el siguiente texto:

\begin{abstract}
"Mujer: hoy puedes soñar. Ahora el sacrificio se justifica. La Patria tiene un lugar para tus hijos. Es un aporte de las Cooperativas a la Restauración Nacional"
\end{abstract}

(El Mercurio, citado por Berríos Muñoz, 2009:

El discurso de la reconstrucción había elegido la figura icónica de la mujer puesto que legitimaba moralmente el golpe militar en un relato de efectividad emocional. Fue ampliamente difundida la versión, narrada por Lucía Hiriart en primera persona, acerca de su desesperación durante los años de la UP, y de cómo ella había entonces fustigado a su marido para que actuase, preguntándole acerca de cuál era verdaderamente el futuro que deseaba para sus hijos ${ }^{26}$. Por otro lado, el 'discurso de la escasez' cobró potencia desde el punto de vista emocional e ideológico. Por lo mismo, la mujer fue el dispositivo a través del cual se explicaba cómo la crisis económica debía ser entendida y sorteada mediante el ingenio de las esposas y madres. En esta línea tanto la Dirección de Industria y Comercio (DIRINCO), la Secretaría Nacional de la Mujer como CEMA-Chile llevaron a cabo programas de educación al consumidor dirigidos a las mujeres, muchos de ellos difundidos a través de la televisión (Valdivia Ortiz de Zárate, 2010). Más allá de las cifras de las estadísticas que muestran en qué medida aumentó o mejoró el consumo y la calidad de vida durante los años del gobierno de Allende, lo cierto es que la Unidad Popular perdió la batalla simbólica acerca del consumo y la familia, puesto que su evocación remite a imágenes de desabastecimiento, de largas colas para conseguir alimentos y de escasez y racionamiento. Esta memoria de lo cotidiano presentaría a las mujeres como 'las principales víctimas del gobierno marxista'.

A su vez, el discurso hacia las mujeres procuró capitalizar la memoria del trauma al identificarlas como dispositivo clave en la agencia primaria de socialización, la familia, insistiendo especialmente

\footnotetext{
${ }^{26} \mathrm{En}$ el mismo sentido, las reiteradas declaraciones, inmediatamente después del golpe, de Gustavo Leigh, comandante en jefe de la Fuerza Aérea e integrante de la Junta de Gobierno (Cf. Power, 2008).
} 
en el papel de reproductoras de los valores tradicionales que las vinculaban 'naturalmente' con los antecedentes 'auténticos' de la historia patria. Por esta vía, se exaltaba la función doméstica del rol femenino, concebido fuera del mercado de trabajo, y como articulador en torno a las nociones convencionales de orden, jerarquía, recato y sumisión (Lechner y Levy, 1984; Valdés, 1985; 1987; Kirkwood, 1986; Valdivia Ortiz de Zárate, 2010).

\begin{abstract}
"Se busca, pues, definir a la mujer doblemente como un eslabón en la esfera de la circulación ideológica: por un lado, se la ubica como receptora de ideologías que reproducen infinitamente su posición subordinada y tradicional dentro de la familia y la sociedad; por otro lado, se la define a ella misma como agente principalísimo de socialización ideológica"
\end{abstract}

(Brunner, 1981: 94).

En el documento La Junta de Gobierno se dirige a las mujeres de $\mathrm{Chile}^{27}$, que corresponde al discurso pronunciado por Augusto Pinochet el 24 de abril de 1974, la Junta de Gobierno agradece a las organizaciones femeninas presentes el esfuerzo en "la lucha de la mujer por la libertad de Chile", el "rol de la mujer en la renovación espiritual de Chile"; se aborda su "participación en el campo del trabajo", la "dignificación de la misión de la mujer", su "participación en las tareas sociales" y "el valor de la colaboración a la política económica", y se agradece:

\begin{abstract}
"A la mujer campesina y a la pobladora, que en medio de las difíciles condiciones económicas del presente nos ofrece el aliciente de una colaboración efectiva y generosa, cuya fe supone para este Gobierno un compromiso de honda responsabilidad.

A las mujeres de nuestros soldados y carabineros, que saben a sus esposos expuestos a todos los riesgos, y han aceptado con abnegación el sacrificio de su vida de hogar, ante el deber de los hombres de armas, que velan noche a noche en resguardo de la paz"
\end{abstract}

(Pinochet Ugarte, 1974b: 4).

Contraria a la visión de madre y esposa abnegada y forjadora de la patria, durante los periodos sucesivos de crisis económicas, particularmente a

\footnotetext{
${ }^{27} \mathrm{El}$ documento lleva por título La Junta de Gobierno se dirige a las Mujeres de Chile. Discurso pronunciado por el Presidente de la Junta de Gobierno, General Augusto Pinochet, en el Edificio Diego Portales, ante varios miles de dirigentes femeninas, el día 24 de abril de 1974.
}

partir de 1982, un número importante de mujeres enfrentó el desempleo de sus hogares incorporándose a un mercado de trabajo precarizado y desregulado (Valdés, 1985; 1986). El desplazamiento de las mujeres desde posiciones subordinadas tradicionales en el hogar hacia posiciones paulatinamente diversificadas en el mercado laboral, impulsado por necesidades de supervivencia, puso en tensión tanto sus capacidades de inserción social y su nivel de empoderamiento, como las relaciones tradicionales de género frente a su papel de jefas de hogar ${ }^{28}$ (Kirkwood, 1986), y -en ciertos segmentos- su grado de visibilidad como sujetos políticos (Valdés, 1987; Palestro, 1991). Este desplazamiento generó una readecuación de los discursos, aunque con anclaje transversalmente conservador, especialmente aquellos referidos a las mujeres pobres, conocidas con la categoría de mujeres de escasos recursos, en la versión oficialista, y más genéricamente como mujeres pobladoras. El discurso oficial siguió viendo en la abstracta categoría de la mujer chilena una imagen de abnegación patriótica, de búsqueda silenciosa del bienestar familiar a pesar de la precariedad, de contención gracias a la anteposición del sacrificio por la patria a su beneficio personal ${ }^{29}$.

Por su parte, el discurso opositor a la dictadura hacía de esas mujeres abnegadas figuras proletarias y proletarizadas que luchaban contra la opresión sistémica encarnada en el trinomio dictaduratradición-neocapitalismo, pero desde el seno mismo de la familia ${ }^{30}$. El argumento que subyace a ambos discursos es la visión esencialista y sacrificial de un ethos de la mujer chilena, agenciado heterónomamente y en función de propósitos ideológico-políticos instrumentales de sesgo autoritario, generalizador y despersonalizado. En ellos las mujeres, especialmente las mujeres pobres, no hablaban, sino que eran habladas. La autoridad moral de las mujeres seguía siendo, por lo demás, proyectada a partir de

\footnotetext{
${ }^{28}$ Grosso modo, se entiende en Chile por 'jefa de hogar' a la mujer asalariada que sustenta por sí misma al grupo familiar, sea por ausencia o inexistencia de un cónyuge o pareja, sea porque éste se encuentra normalmente desempleado o impedido de trabajar.

${ }^{29}$ Este discurso fue difundido principalmente a través de CEMA-Chile (fundación privada que enfatizaba el asistencialismo) y la Secretaría Nacional de la Juventud (organismo gubernamental que enfatizaba el adoctrinamiento explícito). En 1983, año de inicio de las protestas contra el gobierno, CEMA contaba con 6.000 voluntarias que organizaban a 230.000 socias en más de 10.000 centros de madres en todo el país, mientras que la Secretaría Nacional de la Mujer contaba en 1979-1980 con 10.000 voluntarias y 321 sedes en todo el país; "sus actividades habían abarcado más de 2 millones de mujeres entre 1973 y 1983, la mitad de ellas en los últimos dos años" (Lechner y Levy, 1984: 2).

${ }^{30}$ Este discurso fue agenciado por las organizaciones sociales vinculadas a los partidos políticos de oposición, especialmente de la izquierda, por las organizaciones no gubernamentales, por investigadores sociales de centros de estudio privados y por las organizaciones femeninas opositoras lideradas por mujeres de la clase media y alta.
} 
su real o potencial maternidad.

El desarrollo sucesivo y creciente de organizaciones de mujeres con posicionamiento en lo político y en la política, constituido en torno a demandas de democratización y empoderamiento en distintos campos fue, como era obvio, desconocido o invisibilizado por el régimen militar, que optó por aquel discurso más funcional que había podido capitalizar como apoyo moral y simbólico en clave de salvación nacional.

\section{Conclusiones}

La construcción de identidad con atributos determinados a ciertas categorías de sujetos tiene lugar en un contexto marcado por una nueva idea del orden. El orden de lo nacional está constituido aquí por dos ejes estrechamente interrelacionados y que operan al interior de todo contexto cultural: un nivel normativo y un nivel simbólico. El primero se orienta a encauzar las conductas del cuerpo social a través de diferentes dispositivos de disciplinamiento, mientras que el segundo procura dotar de justificación, legitimidad y proyección al discurso en pos de su adhesión y la generación de sentido. En el caso de la mujer chilena durante la dictadura militar se ponen en juego una serie de atributos subyacentes en el imaginario nacional y cuya filiación se encuentra en el repertorio de las corrientes conservadoras tanto de cuño nacionalista como militarista.

Lo primero que puede destacarse al respecto es la concepción de que lo nacional corresponde a una cualidad 'esencial e inmutable', es decir, a una identidad entendida como un conjunto de características nacionales objetivas, sustantivas, únicas y diferenciadoras que convergen en el carácter de la mujer de Chile. Esta concepción deviene en criterio selectivo para calificar moral y políticamente a adeptos y a enemigos sobre la base de la fidelidad a una 'auténtica' e inveterada tradición patriótica.

Un segundo aspecto, vinculado con lo anterior, dice relación con el hecho de que la ancestralidad es uno de los argumentos más importantes en el proceso de legitimación del discurso identitario nacional y en la producción del nuevo imaginario político, que echa mano a un acervo común que nutre y da continuidad a los mitos y tópicos y brinda densidad histórica al arquetipo de la mujer chilena en el Chile bajo dictadura. En este sentido el nuevo régimen se entiende como el tiempo de restauración del sentido perdido y no como una temporalidad de excepción o de ruptura, a fin de proyectar su propia continuidad. Los movimientos de mujeres opositoras a la Unidad Popular encarnan aquí los síntomas de la necesidad de esa restauración.

Un tercer aspecto que es posible observar es un cierto oportunismo ontológico en la discursividad identitaria nacionalista, aspecto que dice relación con su carácter proteico. Si bien es cierto que la identidad nacional es una realidad, dada la capacidad performativa de los discursos sobre ella, su oportunismo queda en evidencia, primero, en los procesos de inclusión/exclusión y de rememoración/olvido de lo que se juzga circunstancial y contextualmente más representativo, más auténtico, más uniforme o más cohesivo en términos de nacionalidad. A este respecto la criba identitaria elidió todos aquellos referentes histórico-culturales asociados a la alteridad femenina amenazante o contestataria: las líderes vinculadas a la política y a las luchas sociales, como las mujeres sufragistas o el Movimiento Pro-Emancipación de las Mujeres de Chile (MEMCH); las intelectuales, artistas y profesionales inspiradas o involucradas en las corrientes modernistas, feministas o en la militancia progresista o revolucionaria. En otros casos no hubo elisión sino transmutación, como ocurrió con figuras emblemáticas de la literatura o el folclore, cuyos casos más evidentes son la transmutación de Gabriela Mistral en inerme poetisa de la maternidad desvalida o de Violeta Parra en romántica cantautora del folclore campesino. Siguiendo esta lógica, la construcción de la tradición poética y folclórica constituye una efectiva estrategia de inclusión pasteurizada de lo popular y lo telúrico en el macrorrelato nacional, en donde no tiene lugar el conflicto.

Un cuarto aspecto se refiere a la permanentemente subyacente estatalidad a partir de la cual se aborda la dimensión del orden, que a su vez permea las demás dimensiones discursivas (temporalidad, espacialidad e identidad). La estatalidad está aquí encarnada en los buenos chilenos, las fuerzas armadas, custodios, intérpretes y garantes del sentir nacional. Su contraparte, las (sus) mujeres, asumen la tarea de colaboración política, sostén privado y apoyo público, conforme a la tradicional asignación de roles de género. A este respecto, la concepción e implementación de acciones de desestabilización política lograron identificar en la matriz de género un soporte diagnóstico suficiente para evaluar y proyectar sus objetivos políticos en un proyecto de signo conservador (en lo político) y anti-izquierdista (en lo partidario).

Finalmente, un quinto y último aspecto a destacar es la alusión a la maternidad como lugar común en torno a la superioridad moral de la mujer. La función reproductiva femenina, entendida como un hecho natural, obvio, necesario y feliz, dotaba a las madres de una autoridad que entronca con el seno de la familia (en lo íntimo), la política sobre los 
cuerpos (en lo estatal), la socialización primaria para la moral cívica y ciudadana (en lo político) hasta con la figura mariana redentora (en lo espiritualreligioso). Tan madre era la Virgen del Carmen, patrona del Ejército, como la procreadora y primera formadora del soldado de la patria; del mismo modo que, con signo contrario, la moral revolucionaria y la lucha social enarbolaban la maternidad sacrificial de la mujer pobladora y obrera, o la maternidad telúrica de la mujer campesina o indígena.

Del análisis aquí presentado se concluye que la dictadura militar, en la construcción de los nuevos referentes identitarios, dio continuidad a un autoritarismo larvado pero omnipresente en la tradición del país, y que los recursos simbólicos para disuadir y persuadir provenían precisamente de ese acervo histórico-cultural capaz de generar tanto sentido y colaboración entre sus adeptos como duración, y aun pervivencia, a su proyecto político-cultural autoritario.

\section{Referencias}

Angenot, M. (2012). El discurso social. Los límites históricos de lo pensable y lo decible. Siglo XXI, Buenos Aires.

Arancibia Clavel, P. y Dittborn, P. (2008). Angustias y esperanzas. La Unidad Popular. En Sagredo, R. y Gazmuri, C., editores, Historia de la vida privada en Chile. Tomo 3: El Chile contemporáneo. de 1925 a nuestros días, pp. 228-255. Taurus/Aguilar, Santiago de Chile.

Arriagada Herrera, G. (1999). El ejército chileno, la $\hat{A}$ «prusianización $\hat{A} » y$ la primera oleada antisocialista (1900-1931). En El pensamiento chileno en el siglo $X X$, pp. 17-63. Ministerio Secretaría General de gobierno de Chile/Instituto Panamericano de GEográfia e Historia/Fondo de Cultura Económica, México D. F.

Aylwin, M., Correa, S., y Piñera, M. (1986). Percepción del rol político de la mujer. Una aproximación histórica. Instituto Chileno de Estudios Humanísticos, Santiago de Chile.

Berríos Muñoz, L. (2009). En busca de un nuevo rostro: fotografías de un discurso dictatorial. Chile, 1973-1976. Comunicación y medios, 20:1-25.

Candina Polomer, A. (2002). El día interminable. Memoria e instalación del 11 de septiembre de 1973 en Chile. En Jelin, E., editor, Las conmemoraciones: las disputas en las fechas in-felices, pp. 9-52. Siglo XXI, Buenos Aires.
Correa S., S., Figueroa G., C., Jocelyn-Holt L., A., Rolle M., C., y Vicuña U., M. (2001). Historia del siglo XX chileno.

Fernández Droguett, R. (2007). Los lugares de la memoria; del golpe y la dictadura militar en Chile: Un análisis autoetnográfico de la marcha del 11 de septiembre. Cuadernos de neuropsicología, 1(2):150-164.

Gaviola, E., Lopresti, L., y Rojas, C. (1988). Centros de madres. ÂLLa mujer popular en movimiento? En ISIS Internacional, editor, Nuestra memoria. Nuestro futuro. Mujeres e historia. ISIS Internacional, Santiago de Chile.

Godoy Ramos, C. (2011). Un pasado en blanco y negro: el imaginario de la Unidad Popular y la nación en el Chile dictatorial'. Revista chilena de antropología visual, 18(1-15).

Gómez, M. (1988). Factores nacionales e internacionales de la política interna del Partido Comunista de Chile (1922-1952). En El Partido Comunista en Chile: Estudio multidisciplinario, pp. 65-139. CESOC-FLACSO, Santiago de Chile.

Hurtado, M., Edwards, P., y Guilisasti, R. (1989). Historia de la TV en Chile (1958-1973). CENECA, Santiago de Chile.

Kirkwood, J. (1986). Ser política en Chile. Las feministas y los partidos. FLACSO, Santiago de Chile.

Kornbluh, P. (2003). The Pinochet File. A Declassified Dossier on Atrocity and Accountability. The New Press, Nueva York.

Labarca Goddard, E. (1968). Chile invadido: reportaje a la intromisión extranjera en Chile. Empresa Editorial Austral, Santiago de Chile.

Lavín, J. (1987). La revolución silenciosa. Zig-Zag, Santiago de Chile.

Lechner, N. (1983). La lucha por el orden en Chile.

Lechner, N. y Levy, S. (1984). Notas sobre la vida cotidiana III: el disciplinamiento de la mujer.

Lira Kornfeld, I. (1991). Psicología de la amenaza política y el miedo. CESOC, Santiago de Chile.

Maldonado Prieto, C. (1989). ACHA y la proscripción del Partido Comunista en Chile, 1946-1948.

Manzi, J., Helsper, E., Ruiz, S., Krause, M., y Kronmüller, E. (2003). El pasado que nos pesa: La memoria colectiva del 11 de septiembre de 1973. Revista de Ciencia Política, 23(2):177-214. 
Montecinos, S. (1997). Dimensiones simbólicas del accionar político y colectivo de las mujeres en Chile. Una propuesta de lectura desde la construcción simbólica del género. En Montecinos, S., editor, Palabra dicha. Escritos sobre género, identidades, mestizajes, pp. 78-94. FLACSO, Santiago de Chile.

Munizaga, G. (1983). El discurso público de Pinochet [Un análisis semiológico] (1973-1976). CLACSO, Buenos Aires.

Palestro, S. (1991). Mujeres en movimiento (19731989).

Pinochet Ugarte, A. (1974a). A seis meses de la liberación nacional. Mensaje al país del Presidente de la Junta de Gobierno, General don Augusto Pinochet Ugarte, pronunciado el día 11 de marzo de 1974. Editora Nacional Gabriela Mistral, Santiago de Chile.

Pinochet Ugarte, A. (1974b). La Junta de Gobierno se dirige a las Mujeres de Chile. Discurso pronunciado por el Presidente de la Junta de Gobierno, General Augusto Pinochet, en el Edificio Diego Portales, ante varios miles de dirigentes femeninas, el día 24 de abril de 1974. Editora Nacional Gabriela Mistral, Santiago de Chile.

Politzer Kerekes, P. (1988). Miedo en Chile. CESOC, Ediciones Chile y América, Santiago de Chile.

Power, M. (1997). La Unidad Popular y la masculinidad. La ventana, 6:250-270.

Power, M. (2008). La mujer de derecha: el poder femenino y la lucha contra Salvador Allende, 19641973. Centro de Investigaciones Diego Barros Arana, Santiago de Chile.

Prado, M. y Krause, M. (2004). Representaciones sociales de los chilenos acerca del 11 de septiembre de 1973 y su relación con la convivencia cotidiana y con la identidad chilena. Psykhe, 13(2):57-72.

Quiroga Zamora, P. (1994). Fuerzas Armadas, sistema político y cosmovisión. Proposiciones, 24:111-116.

Richard, N. (1998). Residuos y metáforas. Ensayos de crítica cultural sobre el Chile de la transición. Cuarto Propio, Santiago de Chile.

Santa Cruz, E. y Santa Cruz, G. (2005). Las escuelas de la identidad. La cultura y el deporte en el Chile desarrollista. LOM/ARCIS, Santiago de Chile.

Tocornal Montt, X. y Vergara Reyes, M. (1998). La memoria del Régimen Militar. Un análisis psicosocial desde la perspectiva socioconstruccionista.

Valdés, T. (1985). Mujer popular: matrimonio, hijos y proyecto. Un estudio de casos.

Valdés, T. (1986). El movimiento poblacional: la recomposición de las solidaridades sociales.

Valdés, T. (1987). Las mujeres y la dictadura militar en Chile.

Valdés, T. y Gomáriz, E., editores (1992). Mujeres latinoamericanas en cifras. Instituto de la $\mathrm{Mu}-$ jer/FLACSO, Santiago de Chile.

Valdés, T., Weinstein, M., Toledo, M., y Letelier, L. (1989). Centros de madres 1973-1989. Â¿Sólo disciplinamiento?

Valdivia Ortiz de Zárate, V. (2010). ÂA $\hat{A}_{¡}$ Estamos en guerra, señores! $\hat{\mathrm{A}} \gg \mathrm{El}$ régimen militar de $\mathrm{Pi}$ nochet y el $\hat{\mathrm{A}}$ puebloÂ», 1973-1980. Historia, 4:163-201.

Varas, A. (1983). Fuerzas armadas y gobierno militar: corporativización y politización castrense. En Chile 1973-198?, pp. 49-63. FLACSO, Santiago de Chile.

Varas, A. y Agüero, F. (1984). El proyecto político militar. FLACSO, Santiago de Chile.

Vergara, P. (1983). Las transformaciones del Estado chileno bajo el régimen militar. En Chile 1973-198?, pp. 65-104. FLACSO, Santiago de Chile.

Vilches Parra, D. (2016). Del Chile de los triunfos morales al $\hat{\mathrm{A}}$ «Chile, país ganador $\hat{\mathrm{A}}$. La identidad nacional y la selección chilena de fútbol durante la dictadura militar (1973-1989). Historia Crítica, 61:127-147.

Waldman Mitnick, G. (2009). Chile: la persistencia de las memorias antagónicas. Política y cultura, 31:211-234.

Whelan, J. (1993). Desde las cenizas. Vida, muerte y transfiguración de la democracia en Chile 18331988. Zig-Zag, Santiago de Chile. 